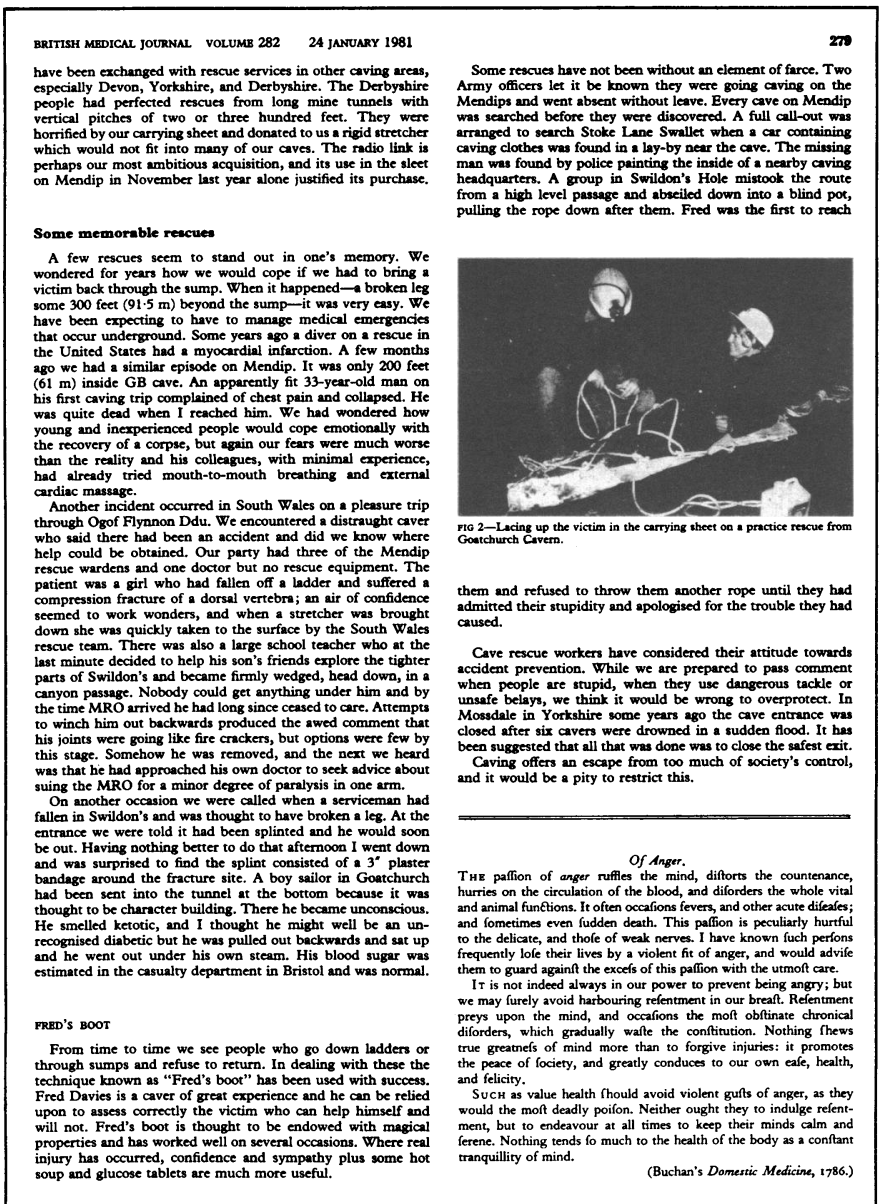

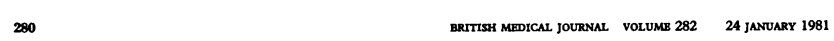

\section{Pitfalls in Practice}

\section{Finding a practice}

I: The adverts

JOHN OLDROYD

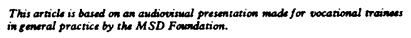

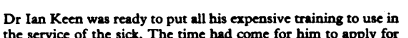

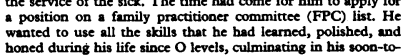

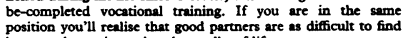

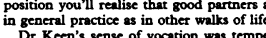

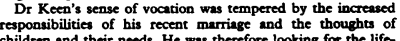

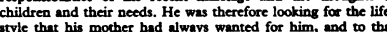

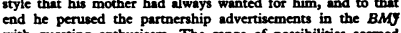

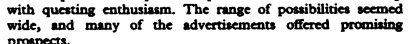

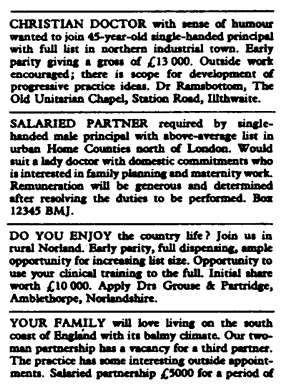

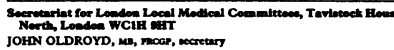
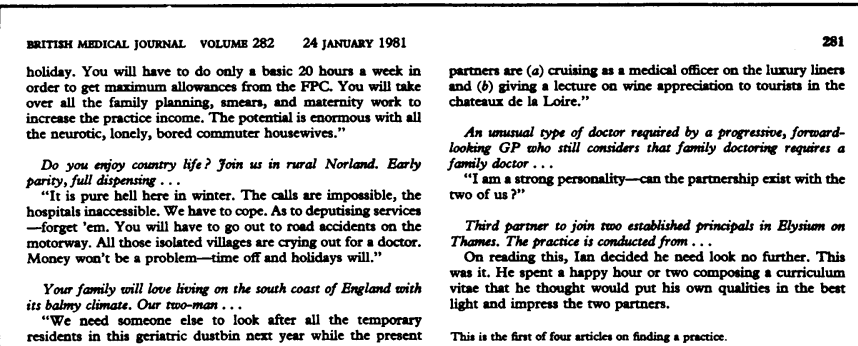

\section{Emergencies in the Home}

\section{The psychiatrically violent patient}

P W SHORT

When considering the violent and paychiartic patient it is imare neither interchangeable nor complementiary and that they
mey be aplied seperately or together. Thus not all violen may be applied separately or together. Thus not all violent
patients will be suffering from paychiatric illness, nor will all

Dingnosis

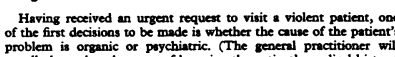

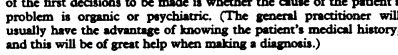

ORGANIC CAUSES INCLUDE:

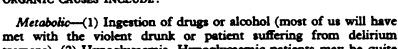

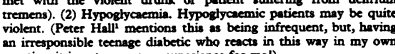

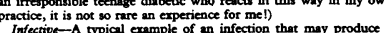

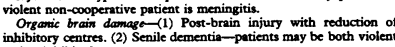
and uninhibited.
Post-epileptic homicidal opisodes

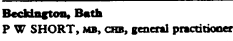

PSYcantrac Causess INCLUDE:

Paranoid stato-Schizophrenic patienss, for example, may some-
times progress to violent behaviour as a result of their delusions of

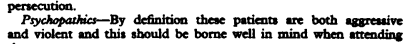
and violent and this sbould be borne well in mind when attending
them
Depressive statar-Depression sometimes resuls in violenoc, which
may be directed outwerdly, inwardly, or both (for example, actempting

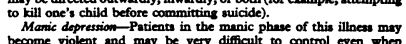

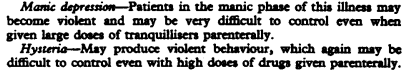

OTHER CAUSES INCLUDE:

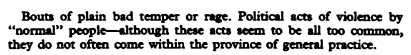

Management

CANBRN APPROACH

Great care must be exercised when confronting a violent patient
who may be very denater the problem). The doctort muat not be seen to be frightened by the

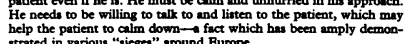

282

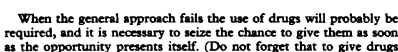

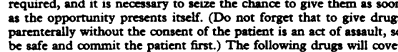

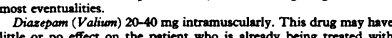

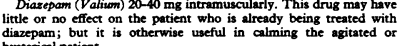

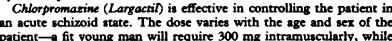

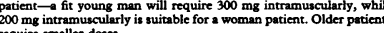

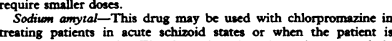

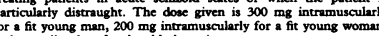

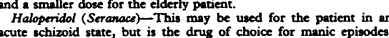

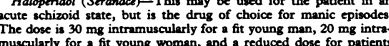

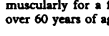

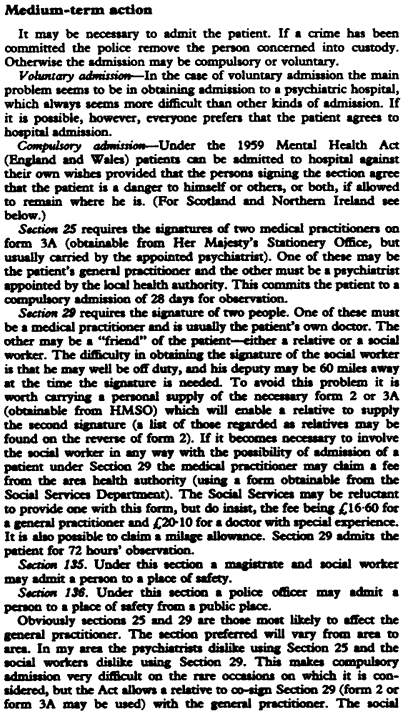

BRITISH MBDICAL JOURNAL VOLUME $282 \quad 24$ JANUARY 1981

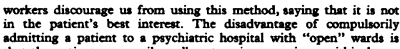
adminting a patient to o p pyychiatric hospital with "open" wards is
chat the paritent may easisy walk out again, sometimes within hours
of having been admitred. Conclusion

While it may not be possible to provide a cure for these patients, violent episode. The general practitioner is in an ideal position to facilinte a change in attitude and management on the part constribute to better conterol of the underlying condition-for
example, once the family of a schizophrenic patient fully
understand the importance of regular medication in the pre-

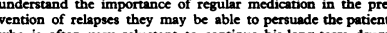
who is often very reluctant to continue his long-term drugs
to take them regularly. It may also be possibbe to explain to
the family that the reduction of tensions and pressure on the patient will cause fewer relapses.

Scotland and Northern Ireland

Soctland and Northern Ireland are covered by differen
Acts but there is no difference in the intent of the Acts The relevant sections of the 1960 Act on Sootland are Section 23 which is equivalent to our Section 25, and Section 31 , which
equivalent to our Section 29 . Sections 135 and 136 are represented in the Scortish Act by Sections 103 and 104. In Northern Ireland the 1961 Act can be involed. My thanka to my wife Suatn, Mrs J Gould, and Mrs A Leocy-Halber

Reference

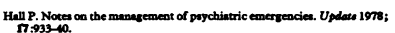

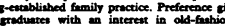

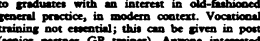

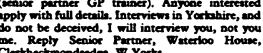

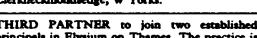

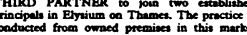

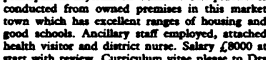

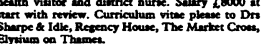

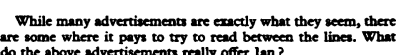
Christian doctor with sense of humour wanned to join 15-year-old Remsbotrom hes soldiered in the trenches for as long at he can and is erchususted. He is aware he is behind the times in practio primery care teamm-but he is willing to treke a substantial cout in income to get belp on his own terms, even if it means fighting
for a clinical assistansohip. It will, however, have to be on his own terms, which metans no immigrants and someone who will
be a sociel friend and will share his cynical apprecition of his loc

Saleried parrener required by single-handed male principal wich "I need someone to give cover fort me when I go off on

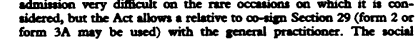

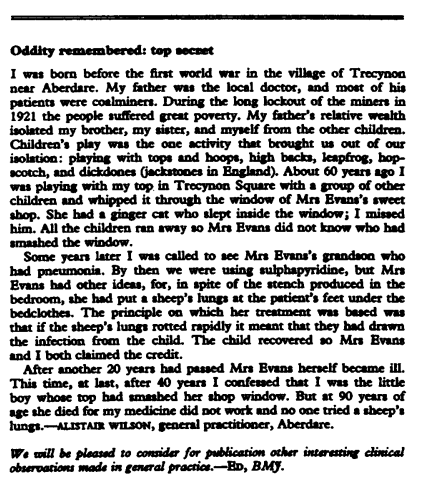

